Solanum tuberosum L. انتاج درينات تقاوي الرتب العليا للبطاطا

باستخدام تقنية زراعة الاتسجة النباتية

\title{
Production high class of micro tuber potato seeds (Solanum tuberosum L.). by Using tissue culture technique
}

علي عبد الامير مهدي الصالحي*

\author{
عبد الجاسم محيسن جاسم الجبوري \\ مركز بحوث الثقنيات الاحيائية / جامعة النهرين

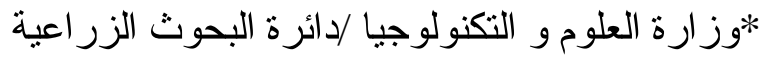

\section{A.A.Al-jibouri}

A.A.Al-salhay*

Biotechnology Research center/Al-Nahrain University

* Ministry of Science and Technology

المستخلص:

هاف البحث انتاج الارينات الدقيقةمن 4 اصناف من البطاطاو هي Escort , Estima , Bintje Premiere في خارج الجسم الحي باستأصال المرستيم القي بطول

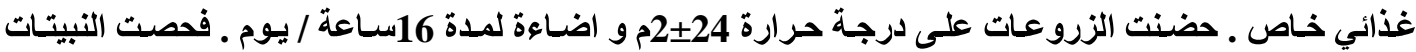

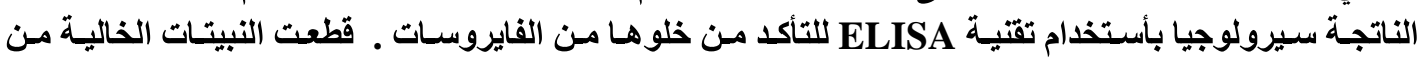

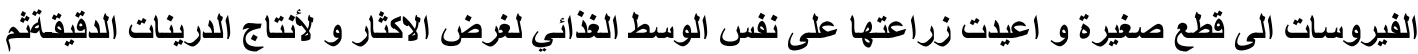

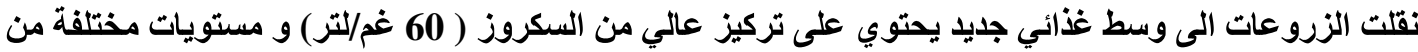

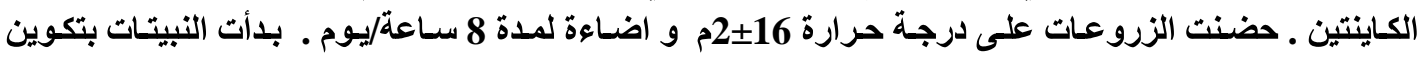
الدرينات الدقيقة بعد 10-8اسبوع ـ اظهرت النتائج وجود اختلافـات معنويـة بين اصناف البطاطـا في استجابته

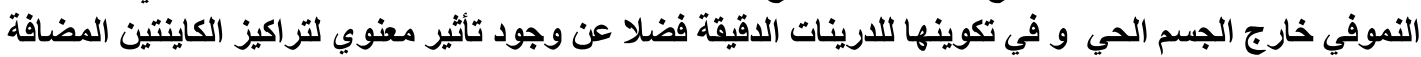

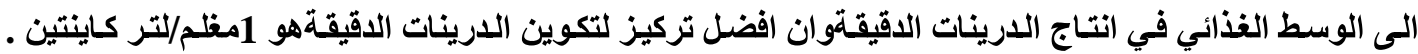

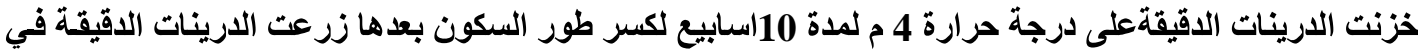

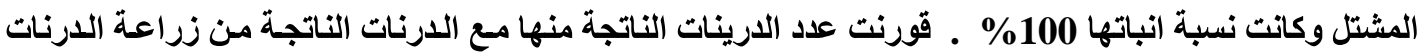

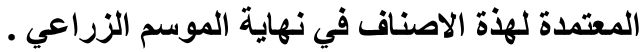

Abstract ;

The aim of this investigation was produced micro tubers of four potato cultivars Premiere, Bintje, Estima and Escort in vitro. Apical meristems (0.2-0.4 mm) of potato cultivars were excised and cultured on nutrient medium and incubated at $24 \pm 2 \mathrm{C}$ ? and 1000 lux light intensity for $16 \mathrm{hrs}$ per day. The developing plantlets were examined serological by using ELISA technique to eliminate the viral infected plantlets. The virus-free plantlets were chopped into pieces with single bud and re cultured on fresh medium for mass propagation. For micro tubers formation in test tubes, the cultures were transferred to another medium containing a high percent of sucrose $(60 \mathrm{~g} / \mathrm{L})$ with different concentrations of kinetin; the cultures were incubated under 16 $\pm 2 \mathrm{C}$ ? and $8 \mathrm{hrs}$ photoperiod. The plantlets formed micro tubers after 8-10 
weeks from culturing. The results showed significant differences among cultivar's in their response to in vitro culture and micro tubers formation. The results also showed that the kinetin concentration had significant effect on micro tubers, and $1 \mathrm{mg} / \mathrm{l}$ kinetin concentration was the best. The micro tubers were stored for 10 week at $4 \mathrm{C}$ ? to break down the dormancy period, and gave $100 \%$ germination under nursery condition. Numbers of tubers derived from micro tubers and normal tubers of these cultivars were compared at the end of season.

المقدمة

البطاطا .Solanum tuberosum Lolanceae من محاصيل العائلة الباذنجانية التي تضم العديد من المحاصيل

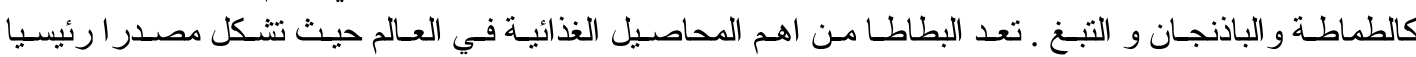

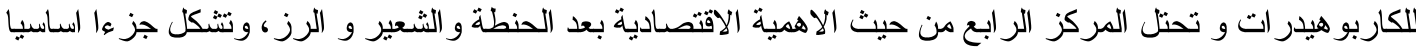

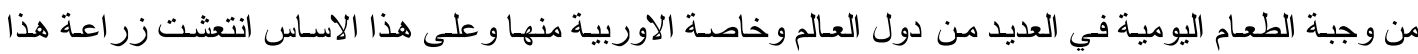

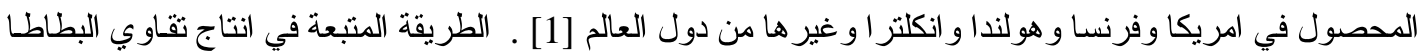

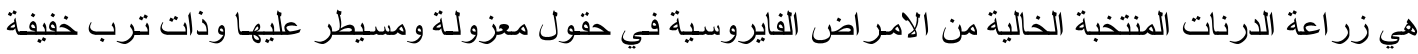

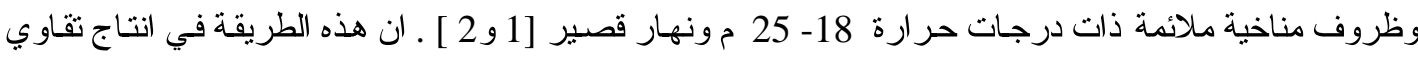

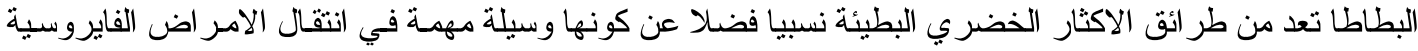

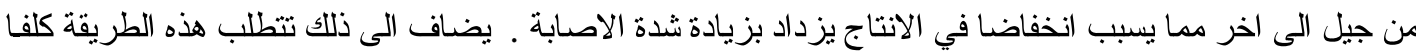

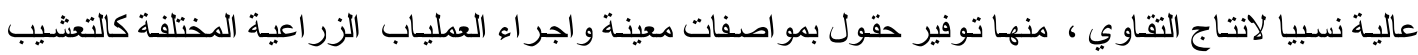

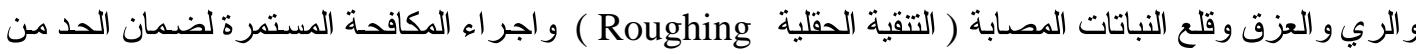

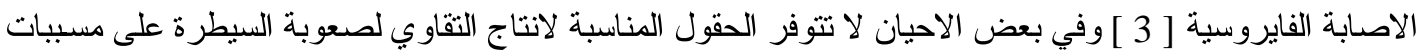

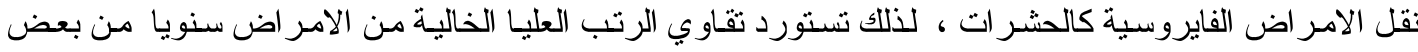

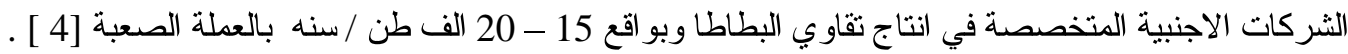

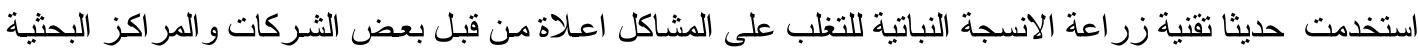

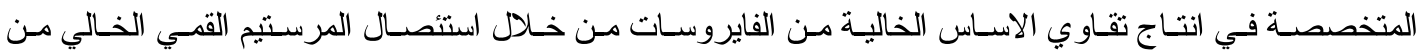

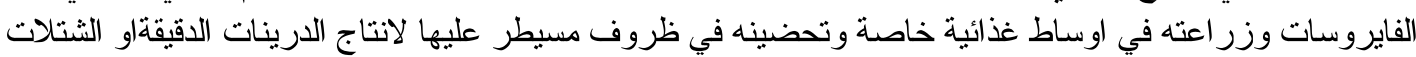

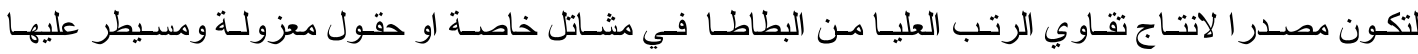

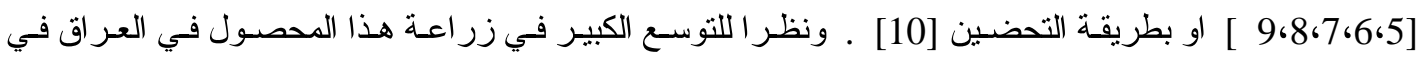

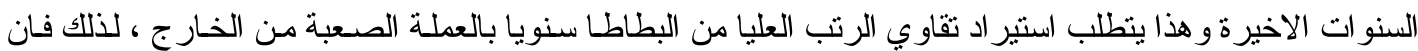

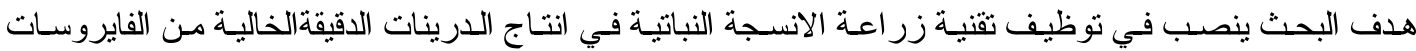

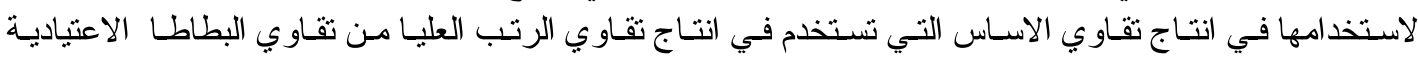

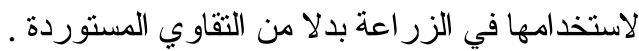

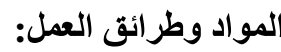

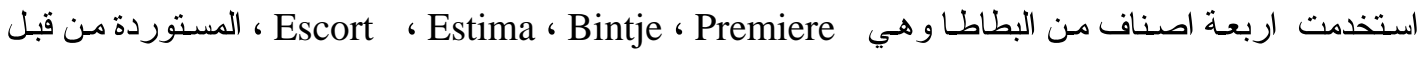

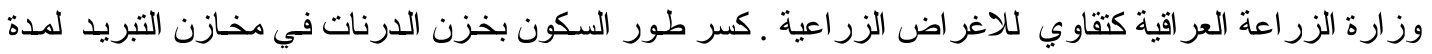

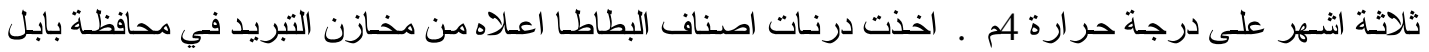

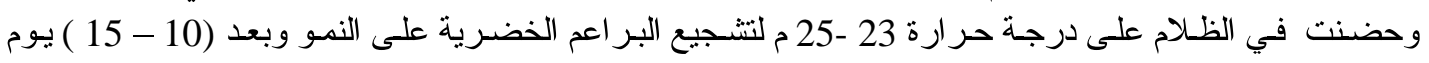

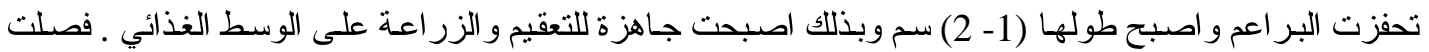

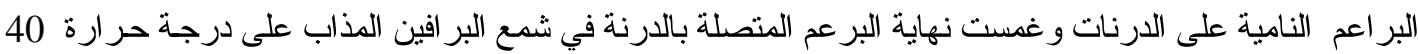

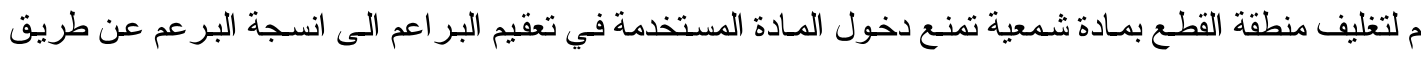

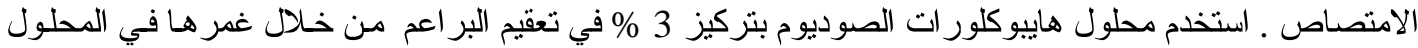

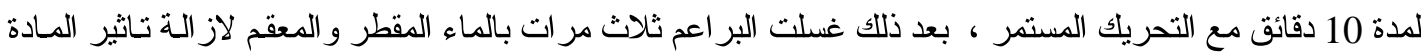

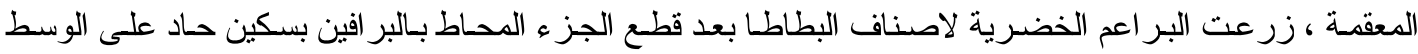

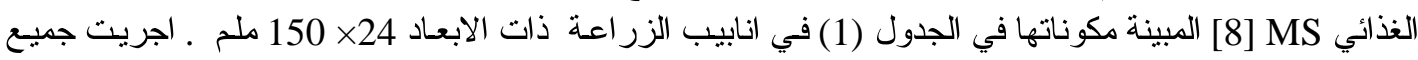




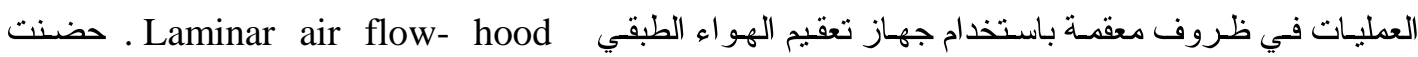

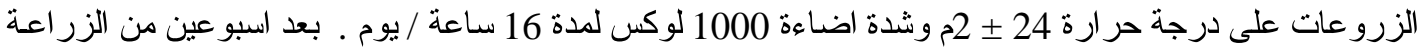

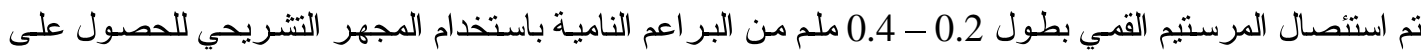

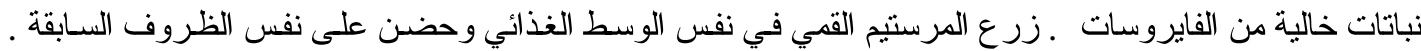

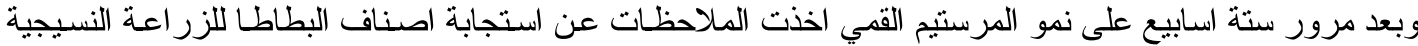

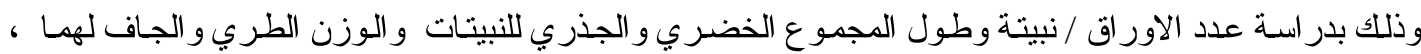

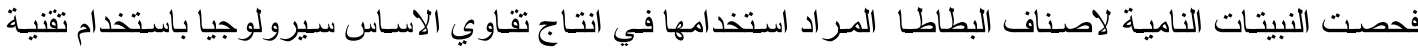
و (11 [ ELISA) Enzyme Linked Immeunosorbent Assay

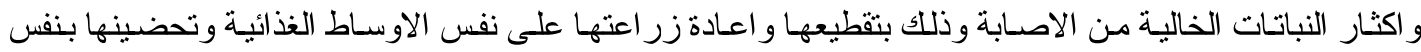

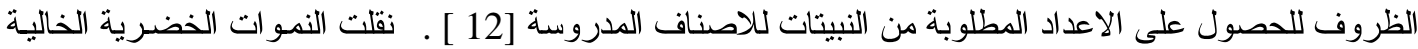

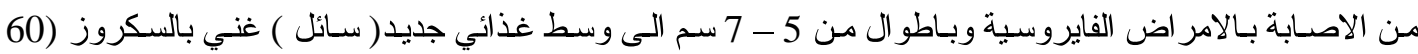

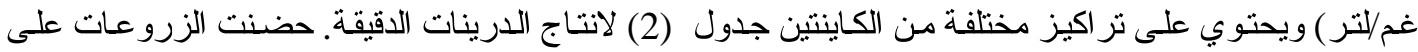

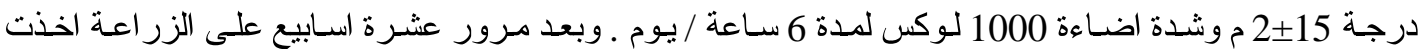

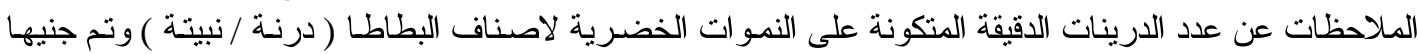

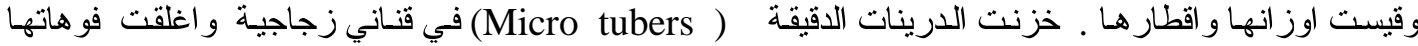

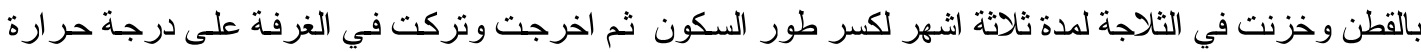

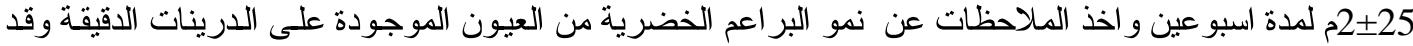

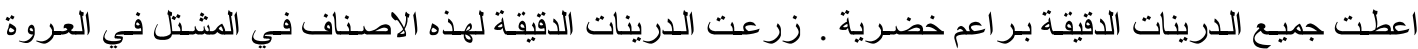

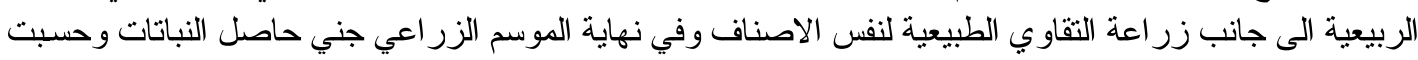

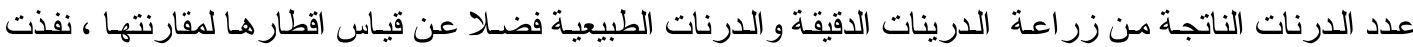

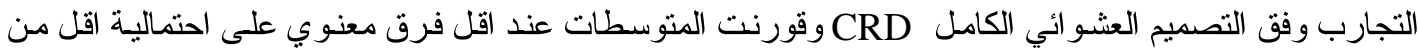

. [13] 0.05

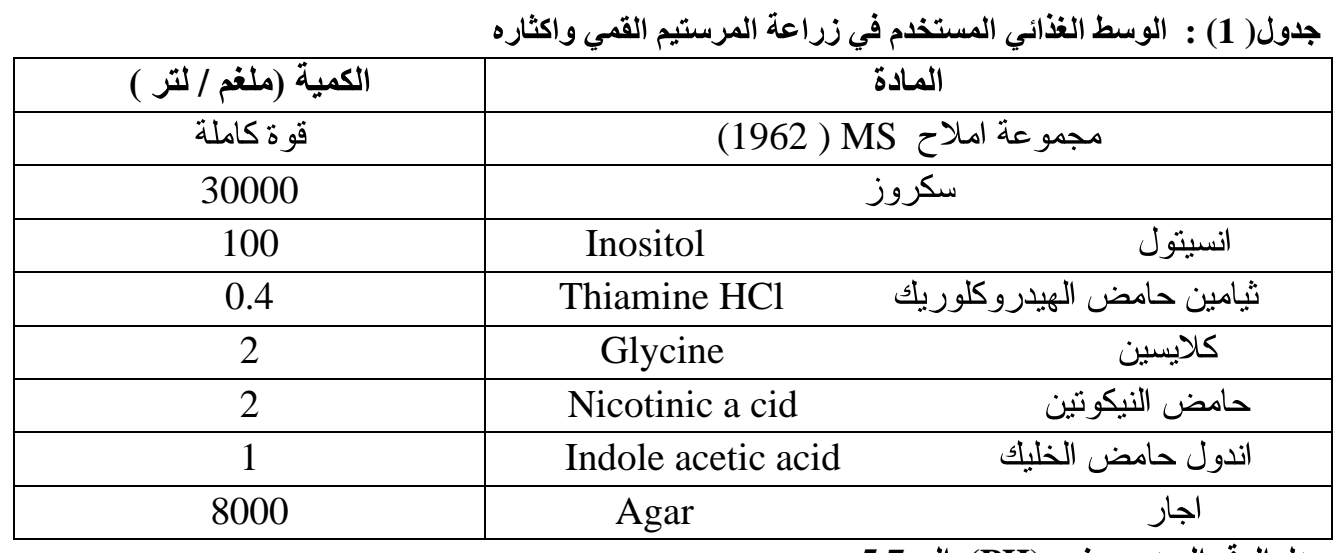

يعدل الرقم الهيدروجيني (PH) الجى 5.7 
جدول ( 2 ) : مكونات الوسط الغذائي المستخدم في انتاج الارينات الدقيقة

\begin{tabular}{|c|c|c|}
\hline الكمية (ملغم / لتز ) & \multicolumn{2}{|c|}{ المادة } \\
\hline قوة كاملة & \multicolumn{2}{|c|}{ مجموعة املاح MS (1962) } \\
\hline 60000 & \multicolumn{2}{|c|}{ سكروز } \\
\hline 100 & Inositol & انسيتول \\
\hline 0.4 & Thiamine $\mathrm{HCl}$ & ثيامين حامض الهيدروكلوريك \\
\hline 2 & Glycine & كلايسين \\
\hline 2 & Nicotinic a cid & حامض النيكوتين \\
\hline $0.0,1,3,5$ & kinetin & الكاينتين \\
\hline 1 & Indole acetic acid & اندول حامض الخليك \\
\hline
\end{tabular}

يعدل الرقم الهيدروجيني (PH) الذي لخيك 5.7

النتائج والمناقشة :

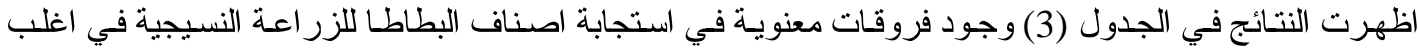

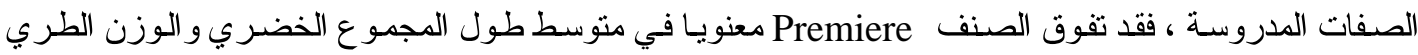

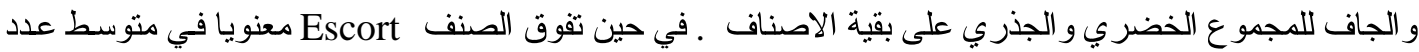

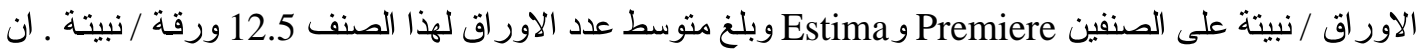

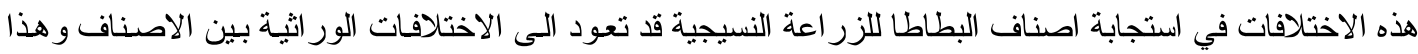
ماكده [14 7 ، 15 ] عند در استهم اكثار بعض اصناف البطاطا بالزر اعة النسيجية .

\begin{tabular}{|c|c|c|c|c|c|}
\hline \multirow{2}{*}{ أ اقل ف فق م معنوي } & \multicolumn{4}{|c|}{ اصناف البطاطا } & \multirow{2}{*}{ الصفات المدروسة } \\
\hline & Escort & Estima & Bintje & Premiere & \\
\hline 1.36 & 7.20 & 9.41 & 9.24 & 13.83 & طول المجموع) \\
\hline 1.59 & 9.30 & 8.00 & 9.74 & 7.50 & طول المجموع الجذري(سم) \\
\hline 1.60 & 12.50 & 10.30 & 11.00 & 10.41 & عدد الاور اق / نبيتة \\
\hline 40.51 & 29.30 & 273.30 & 250.60 & 563.30 & الوزن الطري للمجموع (ملغم) \\
\hline 5.16 & 25.21 & 29.83 & 24.54 & 47.49 & الوزن الجاف للمجموع (ملغم) \\
\hline 15.24 & 109.9 & 68.33 & 84.58 & 133.08 & 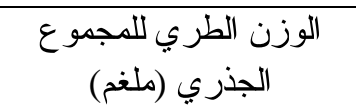 \\
\hline 0.80 & 8.96 & 8.33 & 7.20 & 10.17 & الوزن الجاف للمجموع الجذري (ملغم) \\
\hline
\end{tabular}

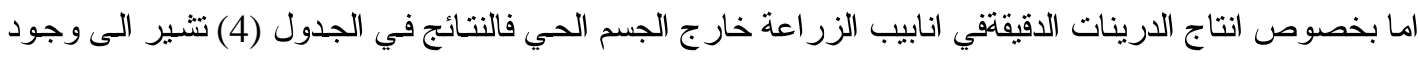

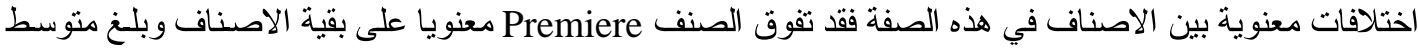

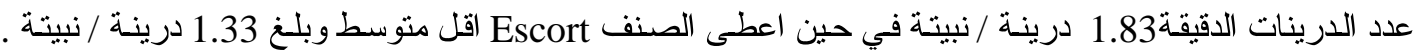

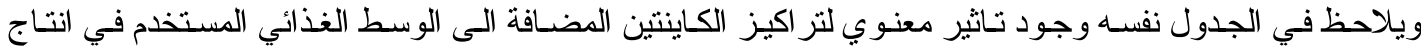

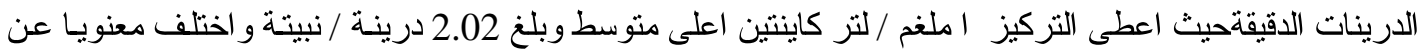

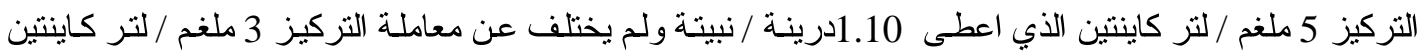

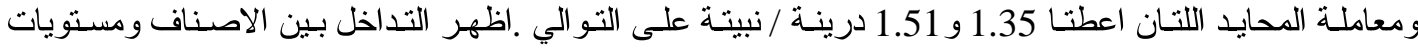
الكاينتين المضافة الى الوسط الغذائي وجود تداخلات معنوية في هذه الصفة حيث اعلي اعطى التركيز 1 ملغم / لتر كاينتين الطين 
في الصنف Premiere اعلى منوسط وبلغ 2.66 درينة / نبيتة و اختلف معنويا عن اغلب التداخلات في حين اعطى

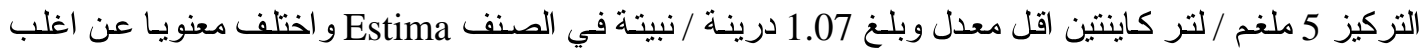

جدول(4) : تاثير تراكيز الكاينتين في عدد الدرينات الدقيقة الناتجة من الزراعة النسيجية لاصناف البطاطا

\begin{tabular}{|c|c|c|c|c|c|}
\hline \multirow[b]{2}{*}{ المتوسط } & \multicolumn{4}{|c|}{ اصناف البطاطا } & \multirow{2}{*}{ الكاينتين ملغم } \\
\hline & Escort & Estima & Bintje & Pemiere & \\
\hline 1.51 & 1.33 & 1.41 & 1.58 & 1.75 & صفر \\
\hline 2.02 & 1.25 & 2.00 & 2.16 & 2.66 & 1 \\
\hline 1.53 & 1.66 & 1.58 & 1.16 & 1.73 & 3 \\
\hline 1.10 & 1.08 & 1.07 & 1.08 & 1.16 & 5 \\
\hline & 1.33 & 1.51 & 1.49 & 1.83 & المتوسط \\
\hline
\end{tabular}

وتبين النتائج وجود تاثير ات معنوية لاصناف البطاطا ومستويات الكاينتين المضـافة الى الوسط الغذائي و التداخل بينهما في متوسطوزن الدرينات الدقيقة جدول (5) ، فقد تفوق الصنف Estima في هذه الصفة على بقية الاصناف

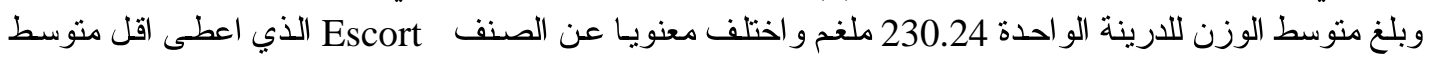

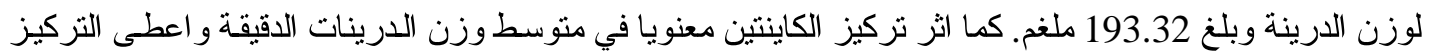

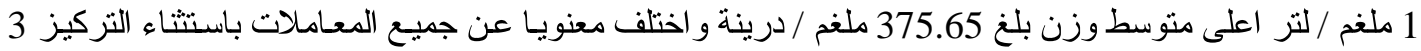

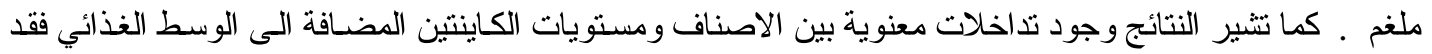

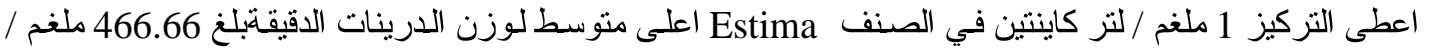

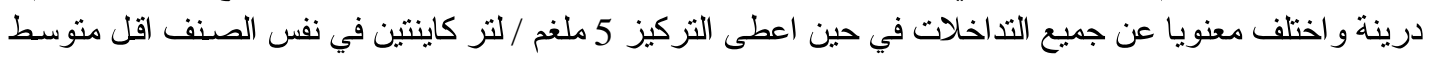

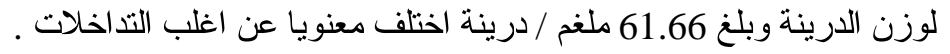

جدول(5) : تاثير تراكيز الكاينتين في وزن الارينات الاقيقة ( ملف) الناتجة من الزراعة النسيجية لاصناف البطاطا

\begin{tabular}{|c|c|c|c|c|c|}
\hline \multirow{2}{*}{ المتوسط } & \multicolumn{4}{|c|}{ اصناف البطاطا } & \multirow{2}{*}{ تاكيز الكاينتين } \\
\hline & Escort & Estima & Bintje & Pemiere & \\
\hline 223.24 & 228.30 & 250.66 & 195.66 & 218.33 & صفر \\
\hline 375.65 & 296.66 & 466.66 & 365.00 & 374.30 & 1 \\
\hline 161.49 & 154.00 & 142.00 & 202.33 & 147.66 & 3 \\
\hline \multirow[t]{2}{*}{102.91} & 94.33 & 61.66 & 102.66 & 153.00 & 5 \\
\hline & 193.32 & 230.24 & 216.41 & 223.35 & المتوسط \\
\hline
\end{tabular}

كما اثرت اصناف البطاطلاوتر اكيز الكاينتين في متوسط اقطسار الدرينات الدقيقةدول (6) ـ فقد تفوق الصنف Premiere

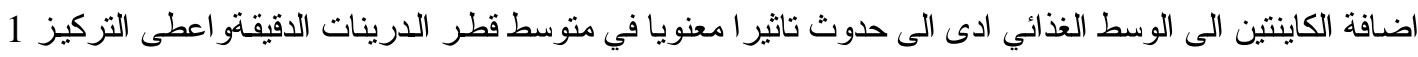

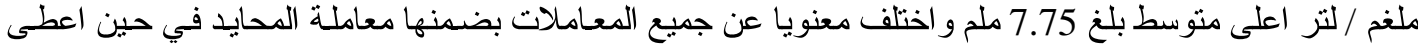

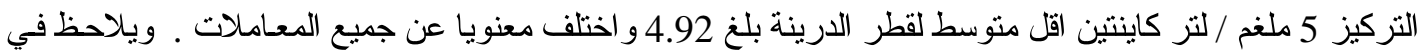

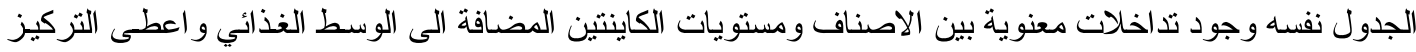

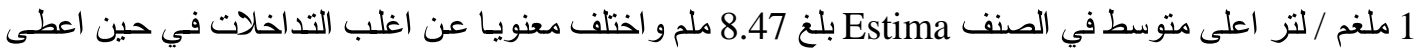
التركيز 5 ملغم / لتر كاينتين للصنف نفسه اقل منوسط وبلغ 3.87 ملم و اختلف معنويا عن اغلب التداخلات . 
جدول(6 ) : تاثير تراكيز الكاينتين في قطر الدرينات الدقيقة ( ملم ) الناتجة من الزراعة النسيجية لاصناف البطاطا

\begin{tabular}{|c|c|c|c|c|c|}
\hline \multirow{2}{*}{ المتوسط } & \multicolumn{4}{|c|}{ اصناف البطاطا } & \multirow{2}{*}{ ملفز / لتر الكــايتتين } \\
\hline & Escort & Estima & Bintje & Pemiere & \\
\hline 6.45 & 6.28 & 6.71 & 6.40 & 6.78 & صفر \\
\hline 7.75 & 6.86 & 8.47 & 7.63 & 8.06 & 1 \\
\hline 5.63 & 5.42 & 5.27 & 6.14 & 5.70 & 3 \\
\hline 4.92 & 4.74 & 3.87 & 5.06 & 6.04 & 5 \\
\hline & 5.82 & 6.08 & 6.30 & 6.64 & المتوسط \\
\hline
\end{tabular}

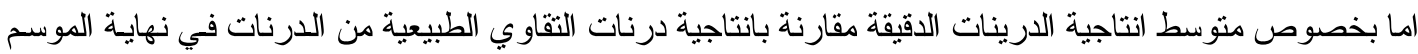

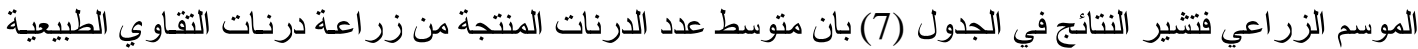
للاصناف قيد الار اسة متفوقة على عدد الدرنات المنتجة من زر اعة الدرينات الدقيقةوكانت الفروقات فئات معنويـة بالنسبة

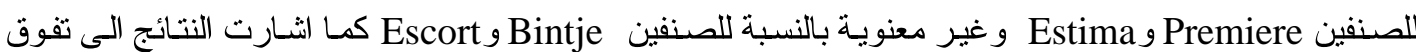
الصنف premiere في منوسط عدد الدرنات المنتجة من زر اعة الدرينات الدقيقة ودرنـات التقاوي الطبيعيـة

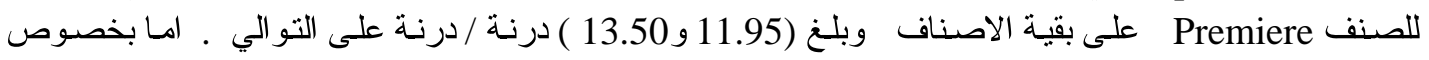

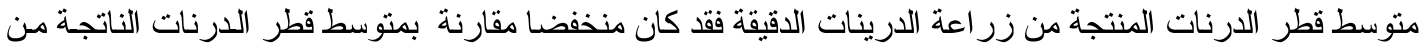

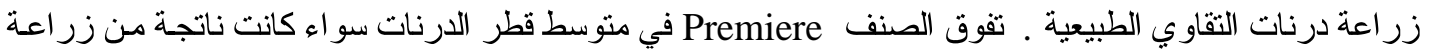

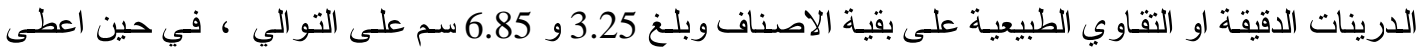
الصنف Estima اقل متوسط لقطر الدرنات وبلغ 2.76 و 5.95 سم على التو الي ايضا .

جدول (7) : مقارنة انتاجية الدرينات الاقيقة والدرنات الطبيعية لاصناف البطاطا المزروعة في المشتل

\begin{tabular}{|c|c|c|c|c|c|}
\hline \multicolumn{2}{|c|}{ متوسط اقطار الارنات الناتجة } & \multirow{2}{*}{ أ ـ. . م } & \multicolumn{2}{|c|}{ متوسط عدد الدرينات / درنة } & \multirow{2}{*}{ صناف البطاطا } \\
\hline الطبيعية & الارقينات & & الطبيعية الارنات & الإقينات & \\
\hline 6.85 & 3.25 & 1.35 & 13.50 & 11.95 & Pemiere \\
\hline 6.32 & 3.21 & N.S & 10.67 & 9.85 & Bintje \\
\hline 5.95 & 2.76 & 1.35 & 11.95 & 10.35 & Estima \\
\hline 6.15 & 2.85 & N.S & 9.54 & 8.92 & Escort \\
\hline
\end{tabular}

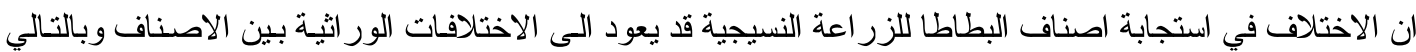

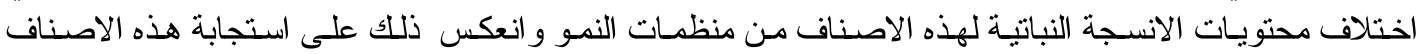

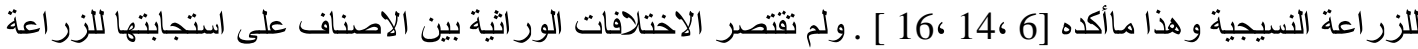

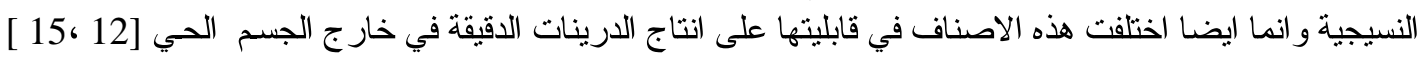

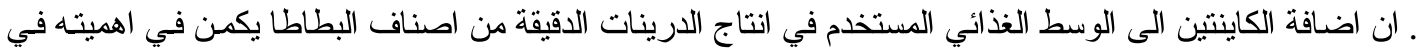

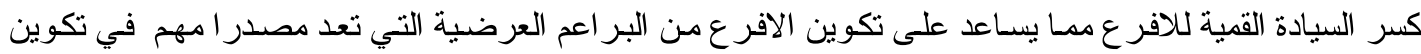

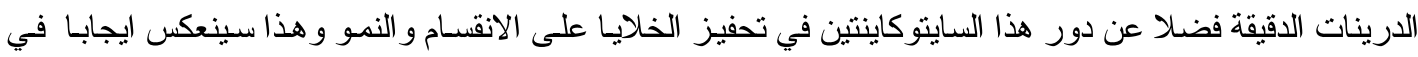

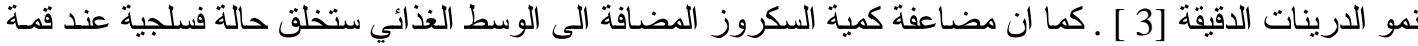

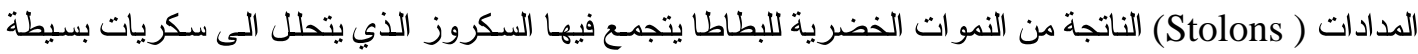

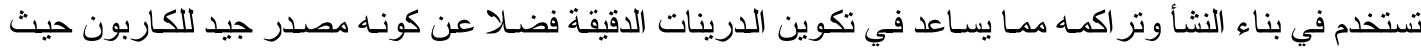
يسهل تمثيله وتحويله الى النشا اللازم لتكوين هذه الدرينات [17 و 18 ] ـ ـ و على العدوم فـان عملية تكوين الدرينات

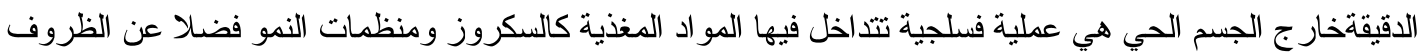
البيئية المحيطة بوسط النشوء [3 ] ـ . ان انتاجيـة الدرينات الدقيقة في المشتل جـاءت مثتاربـة في العدد الى انتاجيـة 


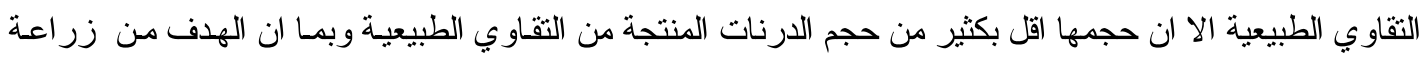

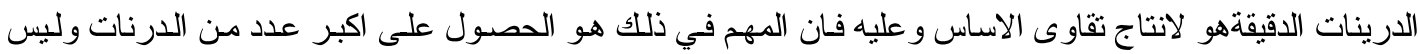

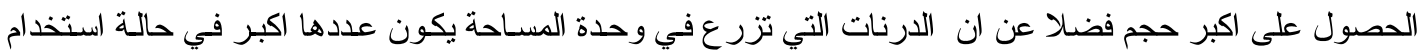

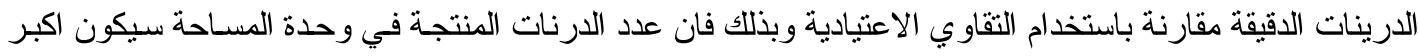

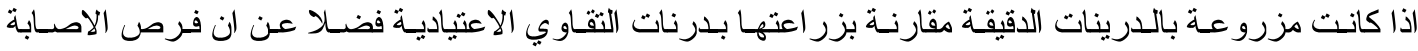

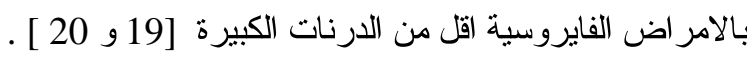

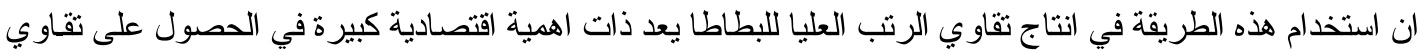

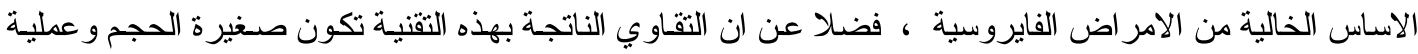

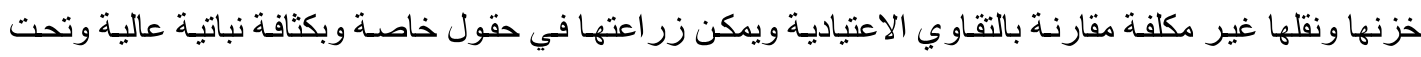

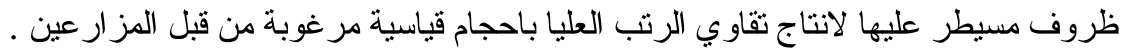

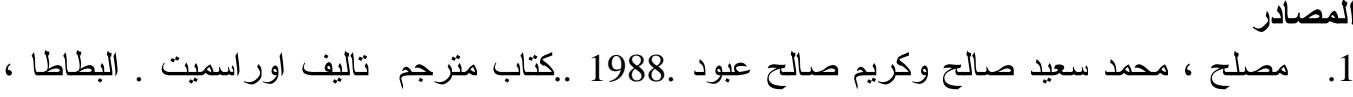

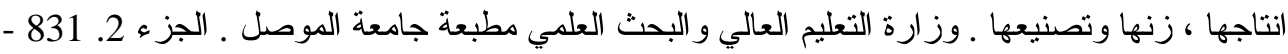

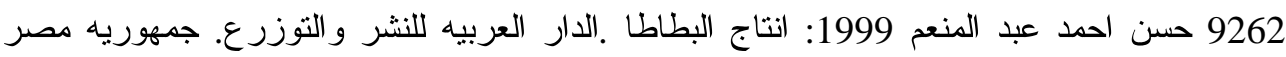

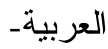

2. Hopkins ,W.G. 1999: Introduction to plant physiology $2^{\text {nd }}$ Ed. John wiley and sons, Inc. USA.-

3.

5. Djurdjina , R.M.Milinkovie and D.Milosevie 1997: in vitro propagation of potato (solanum tuberosum L.). Acta Horticulturae .462:959-963.

6. El.Shobaky, S.A.and Ibrahem I.A.1999: production of potato solanum tuberosum L.through tissue culture techniques . The first Inter. Conf. in Egyption plant tissue culture and its application :12-14 Sep.243-253.

7. Murashige, T.andSkoog,F.1962: A revised medium for rapid growth and bioassays with tobacco tissue cultures. Physiol .plant .15:473-497

8. Najjar ,K.F.1993:Commercialization of the patented microtuber multiplication system of potato. The second arab conference of perspective of modern biotechnology .Amman.Jordan-120-145

9. باستخدام تقنيه التحضين ـ مجله الزر اعه العر اقيه.

10. Clark , M.F. and A.N.Adamas 1977 : Characteristics of enzyme - linked immunosorbent assay for the detection of plant viruses .Gen Virol .34: 475- 485.

11. Wang, Po-Jen and ching- YehH u. 1982: In vitro mass tuberization and virus-free seed potato production in Taiwan. Amer.Potato J. 59:33-37.

12. الساهوكي ، ددحت وكريمة احمد و هيب .1990 : نطبيقات في تصميم وتحليل التجارب ـ وزارة التعليم

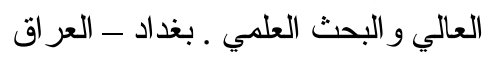

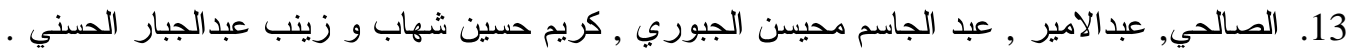

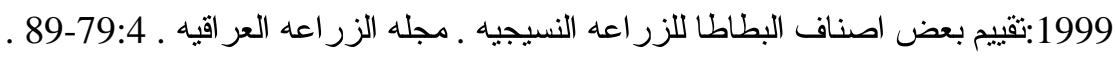

14. Rosell ,G.,.DE.Bertoldi ,F.G. and Tizio, R..1987 In vitro mass tuberization as a contribution to potato micro propagation . Potato Res. 30:111-116. 
15. الصالحي , علي عبد الامير , عبدالجاسم محيسن الجبوري , صادق قاسم البياتي و اوعاد متعب خليل .

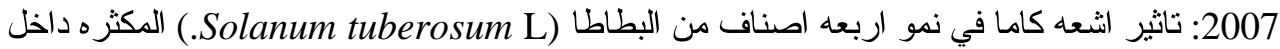

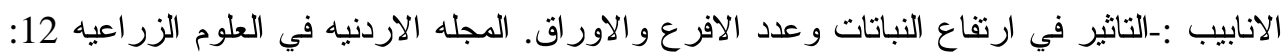
$.289-283$

16. حمزه، موسى محمد 2007: تاثير الفحم المنشط الفعال ونوع العقل في تكوين الدرنات الدقبقه للبطاطا

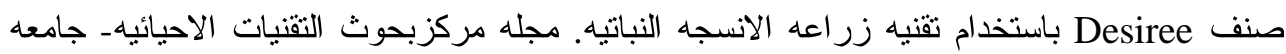

$$
25-16.11 \text { - النهرين }
$$

17. Hones, M.S.2003:The effect of sucrose concentration on micro propagation of potato (solanum tuberosum L-) .Amer .Potato Res. 80:103-115.

18. الرفاعي ,عبد الحليم توفيق وسمير عبدالرزاق الثويكي 2002:ثقنيات القرن 21 لتحسين النبات باستخدام

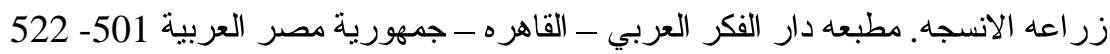

19. Wattimena, G.B.McCowen and Weis, G.1993: comparative field performance of potato from micro tuber. Amer.Potato J.60:27-33. 